Anne E. Hasselmann

Wie der Krieg ins Museum kam

Public History - Angewandte Geschichte | Band 14 
Anne E. Hasselmann, geb. 1986, ist wissenschaftliche Mitarbeiterin im Historischen Museum Basel. 2019 promovierte sie mit einem Doc.CH-Stipendium des Schweizerischen Nationalfonds im Bereich der Osteuropäischen Geschichte an der Universität Basel. Hier lehrte, forschte und publizierte sie zur Geschichte der Sowjetunion im Zweiten Weltkrieg und zur angewandten Museologie. 
Anne E. Hasselmann

\section{Wie der Krieg ins Museum kam}

Akteure der Erinnerung in Moskau, Minsk und Tscheljabinsk, 1941-1956 
Die Open-Access-Ausgabe wird publiziert mit Unterstützung des Schweizerischen Nationalfonds zur Förderung der wissenschaftlichen Forschung.

\section{Bibliografische Information der Deutschen Nationalbibliothek}

Die Deutsche Nationalbibliothek verzeichnet diese Publikation in der Deutschen Nationalbibliografie; detaillierte bibliografische Daten sind im Internet über http://dnb.d-nb.de abrufbar.

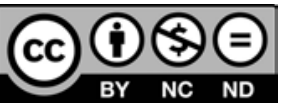

Dieses Werk ist lizenziert unter der Creative Commons Attribution-NonCommercial-NoDerivs 4.0 Lizenz (BY-NC-ND). Diese Lizenz erlaubt die private Nutzung, gestattet aber keine Bearbeitung und keine kommerzielle Nutzung. Weitere Informationen finden Sie unter

https://creativecommons.org/licenses/by-nc-nd/4.o/deed.de

Um Genehmigungen für Adaptionen, Übersetzungen, Derivate oder Wiederverwendung zu kommerziellen Zwecken einzuholen, wenden Sie sich bitte an rights@transcript-publishing.com

Die Bedingungen der Creative-Commons-Lizenz gelten nur für Originalmaterial. Die Wiederverwendung von Material aus anderen Quellen (gekennzeichnet mit Quellenangabe) wie z.B. Schaubilder, Abbildungen, Fotos und Textauszüge erfordert ggf. weitere Nutzungsgenehmigungen durch den jeweiligen Rechteinhaber.

\section{(C) 2022 transcript Verlag, Bielefeld}

Umschlaggestaltung: Maria Arndt, Bielefeld

Umschlagabbildung: Marija Nazarova bei der Führung einer Mädchenschulklasse im Zentralmuseum der Roten Armee, Moskau Dezember 1946, Fotografin/ Fotograf unbekannt, (c) CMVS.

Lektorat: Janika Rüters

Druck: Majuskel Medienproduktion GmbH, Wetzlar

Print-ISBN 978-3-8376-5980-1

PDF-ISBN 978-3-8394-5980-5

https://doi.org/10.14361/9783839459805

Buchreihen-ISSN: 2700-8193

Buchreihen-eISSN: 2703-1357

Gedruckt auf alterungsbeständigem Papier mit chlorfrei gebleichtem Zellstoff. Besuchen Sie uns im Internet: https://www.transcript-verlag.de Unsere aktuelle Vorschau finden Sie unter www.transcript-verlag.de/vorschau-download 